\title{
AVALIAÇÃo DE MANIFESTAÇÕES PATOLÓGICAS EM SISTEMA HIDRÁULICO DE ÁGUA FRIA EM EDIFÍCIO RESIDENCIAL MULTIFAMILIAR
}

\author{
BITTENCOURT FORTE, LAÍS \\ Arquiteta e Urbanista \\ Universidade do Sul de Santa Catarina \\ SC; Brasil \\ laisbitten@gmail.com
}

\author{
LUIZ STOCCO, JOELCIO \\ Engenheiro Civil \\ Universidade Federal de Santa Catarina \\ SC; Brasil \\ eng.stocco@gmail.com
}

\section{RESUMO}

As instalações hidráulicas lideram a ocorrência de manifestações patológicas nos edifícios. Com o processo de verticalização nas cidades, há uma tendência ao surgimento de problemas hidráulicos resultantes do próprio porte das obras. O desempenho insatisfatório do sistema, além de resultar em danos físicos e psicológicos aos usuários, geralmente está acompanhado do desperdício de água e de prejuízos financeiros. Essas falhas podem ter origem na fase de projeto, execução ou uso, onde as anomalias poderão ser decorrentes da operação e manutenção das instalações. Neste estudo o intuito foi identificar as possíveis causas de rompimentos em tubulações hidráulicas do sistema de água fria em edifício residencial multifamiliar após a substituição dos registros de gaveta do barrilete e também sugerir intervenções no sistema para eliminar os danos. Realizou-se uma inspeção in loco no sistema hidráulico de água fria do edifício, utilizando um fluxograma de atividades e ensaios complementares em conjunto da anamnese. O procedimento foi baseado em duas etapas de vistoria técnica, barrilete e unidades autônomas, onde realizaram-se ensaios para verificação das pressões estática e dinâmica em pontos específicos do sistema. Através da utilização do manômetro, verificou-se que as pressões estavam com valores acima do máximo determinado pela NBR 5626 (ABNT, 1998), ocasionando sobrepressões no sistema e o rompimento de tubulações. Ao final foram apresentadas propostas para que fossem eliminados os problemas, tais como: instalação de válvulas automáticas redutoras de pressão; esvaziamento das tubulações para a retirada do ar acumulado e abertura gradativa dos registros de gaveta; e troca de peças deterioradas. Palavras-chave: sistema hidráulico, registro de gaveta, pressão estática, pressão dinâmica.

\section{ABSTRACT}

Hydraulic installations lead to pathological manifestations in buildings. With the process of verticalization in cities, there is a tendency to arise hydraulic problems that may be caused by the size of the works themselves. Poor system performance, in addition to causing physical and psychological harm to users, is often accompanied by water wastage and financial loss. These failures may originate at the design, execution, or use phase, where anomalies may be saved in the operation and maintenance of the facility. In this study, the aim was to identify as possible causes of breakages in hydraulic pipelines of the cold water system in multifamily residential buildings after replacing barrel drawer records and also suggest not using the system to eliminate damage. An on-site inspection of the building's cold water hydraulic system was performed using a flowchart of activities and complementary joint anamnesis trials. The procedure was based on two stages of technical visit, barrel and autonomous units, where tests were performed to verify static and heard pressures at specific points of the system. Through the use of the pressure gauge, it was verified that the pressures were above the maximum limit determined by NBR 5626 (ABNT, 1998), causing system overpressures and pipe rupture. In the end, proposals were implemented to eliminate problems, such as: installation of automatic pressure reducing valves; emptying of the pipes for air removal and gradual opening of the drawer registers; and exchange of deteriorated parts.

Keywords: hydraulic system, drawer register, static pressure, dynamic pressure. 


\section{INTRODUÇÃO}

Estudos apontam que $75 \%$ das manifestações patológicas decorrem de problemas relacionados às instalações hidrossanitárias. Essas falhas podem ter origem na fase de projeto, na qualidade do material, na fase de execução ou na fase de uso, onde os danos poderão estar relacionados à operação e manutenção das instalações (CARVALHO JÚNIOR, 2018; PADARATZ, 1991).

A ocorrência dessas manifestações patológicas resulta em custos adicionais, ações jurídicas e inclusive na perda de confiança na empresa responsável pela construção do edifício. Segundo Thomaz (2014), tratar as construções como eternas sem a realização de qualquer tipo de intervenção para corrigir os desgastes que os sistemas construtivos apresentam ao longo da sua vida útil, é um grande erro.

Vários fatores podem diminuir a vida útil esperada originalmente de um patrimônio já construído, como ausência de manutenção e erros de concepção, projeto e execução. De acordo com a NBR 15575 (ABNT, 2013), para o sistema hidrossanitário a vida útil de projeto mínima a ser considerada é de 20 anos para as instalações embutidas e enterradas e de 4 anos para as instalações aparentes e de fácil substituição.

É preciso que os edifícios adotem um sistema de inspeção periódico, para verificar se os cálculos de vida útil feitos em projeto estão acontecendo na prática. Esse monitoramento vai permitir ajustar as previsões ou intervir, caso sejam detectados problemas não considerados previamente, evitando acidentes, preservando vidas e o patrimônio e evitando futuras manifestações patológicas que comprometam o uso e o funcionamento das instalações prediais.

Este estudo refere-se à identificação das possíveis causas dos rompimentos em tubulações hidráulicas do sistema de água fria em edifício residencial multifamiliar após a substituição dos registros de gaveta do barrilete e também à sugestão de intervenções no sistema para eliminar os danos.

\section{EQUIPAMENTOS E MÉTODOS}

\subsection{Equipamentos}

Para a verificação das pressões estática e dinâmica no sistema hidráulico de água fria foi utilizado o manômetro com rosca de 3/4 P2A (características: $0-14 \mathrm{~kg} / \mathrm{cm}^{2}$ ) e para a confirmação das mesmas foi utilizada a bomba de teste hidrostático Rothenberger RP30 de 4,5L (características: 0-30 bar), conforme apresentado na Figura 1.
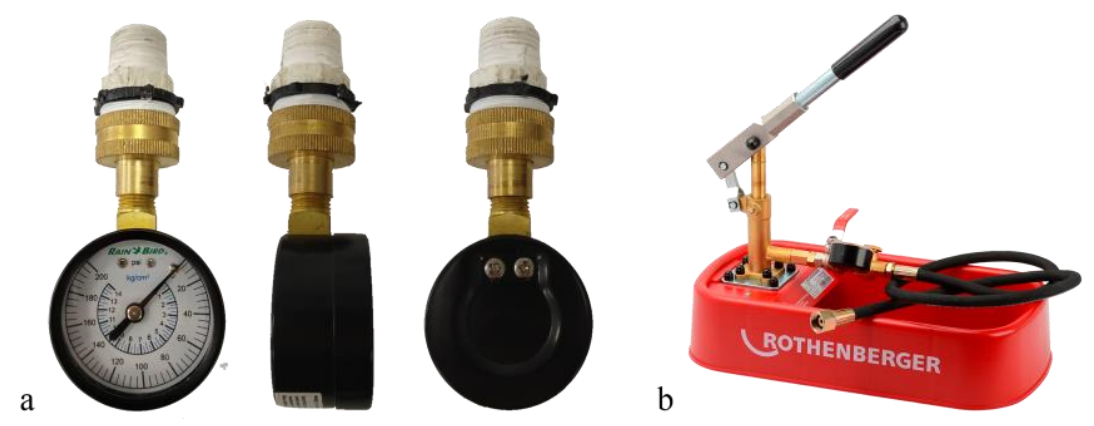

Figura 1: Manômetro (a) e bomba de teste hidrostático (b).

\subsection{Métodos}

Para avaliar as manifestações patológicas existentes no sistema hidráulico de água fria do edifício residencial multifamiliar em estudo, realizou-se uma inspeção in loco utilizando os sentidos humanos e instrumentos para ensaios complementares, em conjunto da anamnese para a obtenção de informações orais com o síndico, zelador e moradores. A metodologia foi baseada no fluxograma proposto por Lichtenstein exposto na Figura 2. 


\section{MANIFESTAÇÃO PATOLÓGICA}

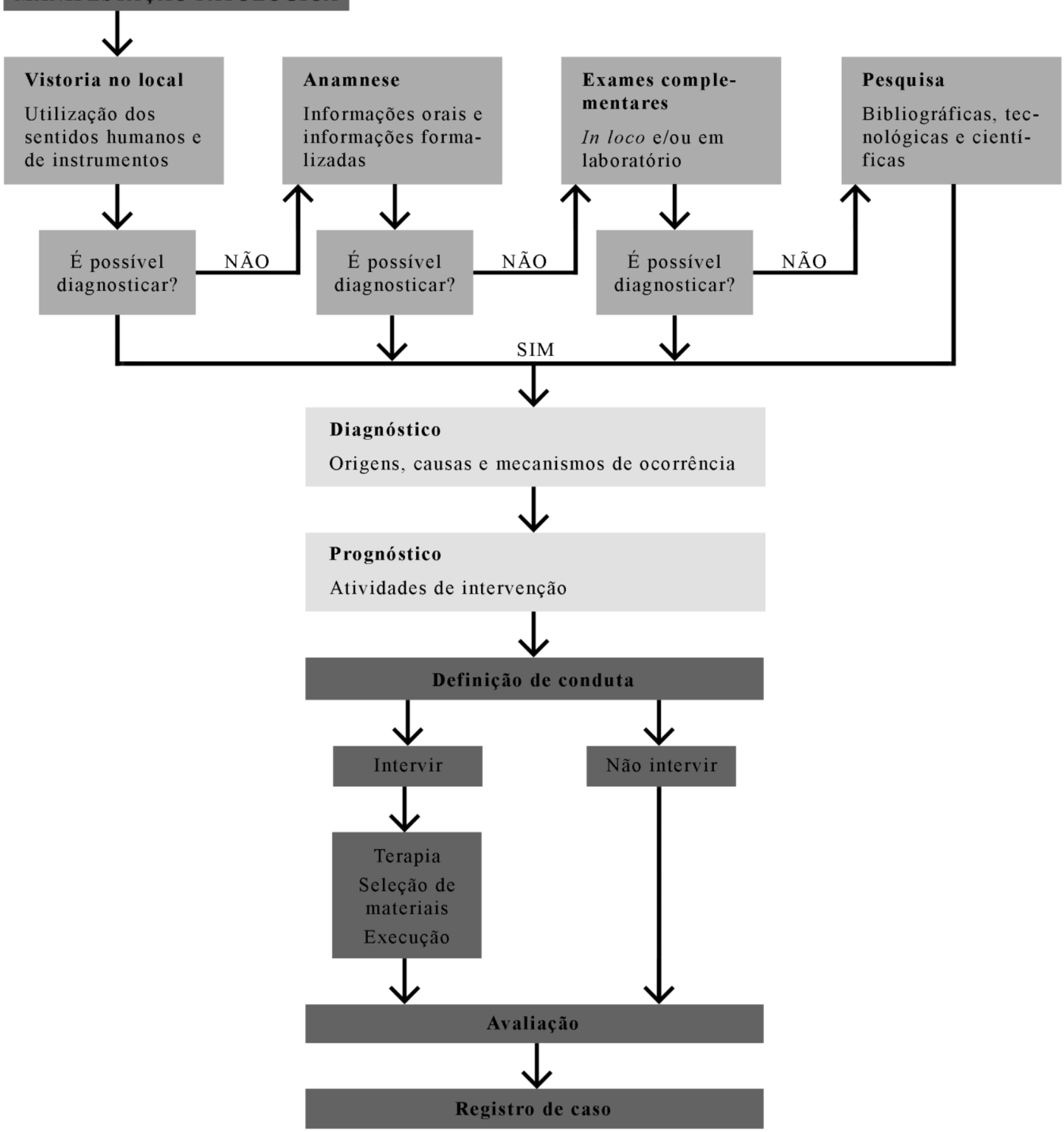

\section{Etapas:}

Levantamento de subsídios

Diagnóstico

\section{Definição da conduta}

Figura 2: Fluxograma de Lichtenstein - Metodologia para a formulação do diagnóstico de manifestações patológicas e da definição de conduta.

Fonte: Adaptado de Lichtenstein (1985).

O procedimento da inspeção in loco consistiu em duas etapas de vistoria técnica, barrilete e unidades autônomas, onde realizaram-se ensaios para verificação das pressões estática e dinâmica em pontos específicos do sistema.

Teve-se acesso às unidades autônomas 101, 501 e 601, sendo que: 
a. Unidade 101 (acesso aos três banheiros da área íntima): no banheiro da suíte denominada "menor" o registro de gaveta não estava interrompendo completamente o fluxo de água, não sendo possível a realização dos ensaios; no banheiro do corredor dos quartos o registro de gaveta estava interrompendo completamente o fluxo de água, mas não fez-se possível a retirada do chuveiro para a realização dos ensaios; e no banheiro da suíte principal denominada "maior" o regisro de gaveta estava interrompendo completamente o fluxo de água, o que permitiu a realização dos ensaios apenas no ponto de ducha higiênica, visto que o sistema de água fria do chuveiro estava impossibilitado de abrir;

b. Unidade 501 (acesso à dois banheiros da área íntima): tanto no banheiro do corredor dos quartos quanto no banheiro da suíte principal denominada "maior" o registro de gaveta não estava interrompendo completamente o fluxo de água e também não havia pontos disponíveis para a realização dos ensaios;

c. Unidade 601 (acesso à um banheiro da área íntima): no banheiro da suíte principal denominada "maior" o registro de gaveta não estava interrompendo completamente o fluxo de água, mas foi possível a realização dos ensaios no ponto de saída de água fria do bidê;

d. Lavabos das unidades autônomas: encontravam-se com o sistema de água fria interrompido, não sendo possível a realização dos ensaios.

Portanto, a realização dos ensaios para a verificação das pressões estática e dinâmica existentes no sistema hidráulico de água fria se deu apenas nos pontos de ducha higiência e do bidê da suíte principal dos apartamentos 101 e 601 , respectivamente, devido às condições de acesso aos pontos de água fria.

Através do fluxograma apresentado na Figura 3 é possível verificar as etapas realizadas para a execução dos ensaios.

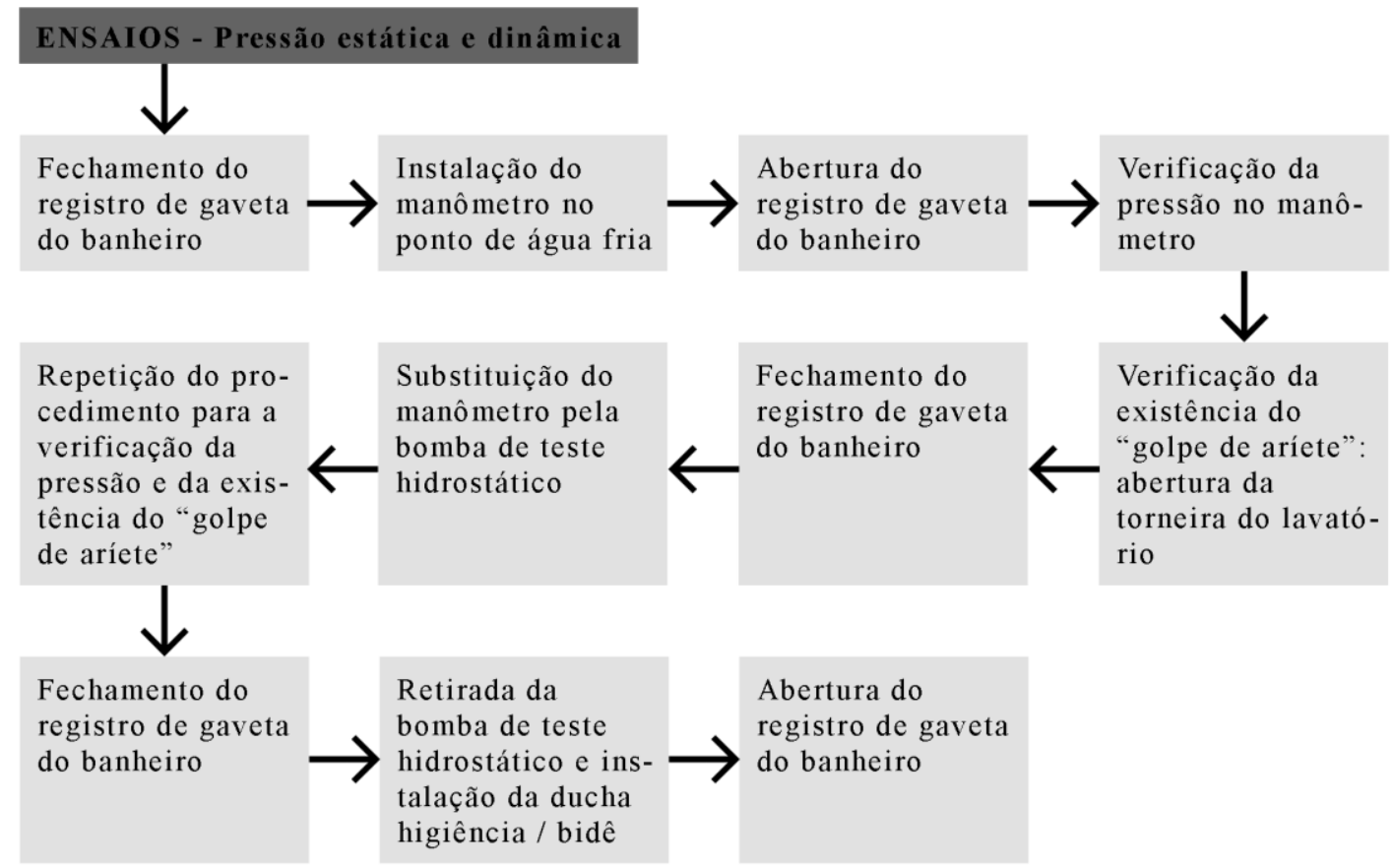

Figura 3: Fluxograma de execução dos ensaios de medição das pressões estática e dinâmica.

De acordo com a anamnese realizada inicialmente com o síndico, zelador e moradores verificou-se que:

a. O edifício de 14 pavimentos estava com idade aproximada de 25 anos;

b. Antes da susbtituição dos registros de gaveta do barrilete não havia ocorrido rompimentos nas tubulações;

c. O síndico do edifício suspeitou da abertura abrupta e sequencial dos registros de gaveta do barrilete como o fator responsável pela ocorrência de diversos rompimentos das tubulações hidráulicas;

d. O síndico do edifício, devido os rompimentos das tubulações, abriu apenas $60 \%$ dos registros de gaveta do barrilete e questionou a possibilidade de abertura de $100 \%$ dos mesmos;

e. O síndico do edifício questionou se os registros de gaveta possuíam maior vazão do que previsto em projeto;

f. O síndico do edifício questionou o que alterou a pressão do sistema. 


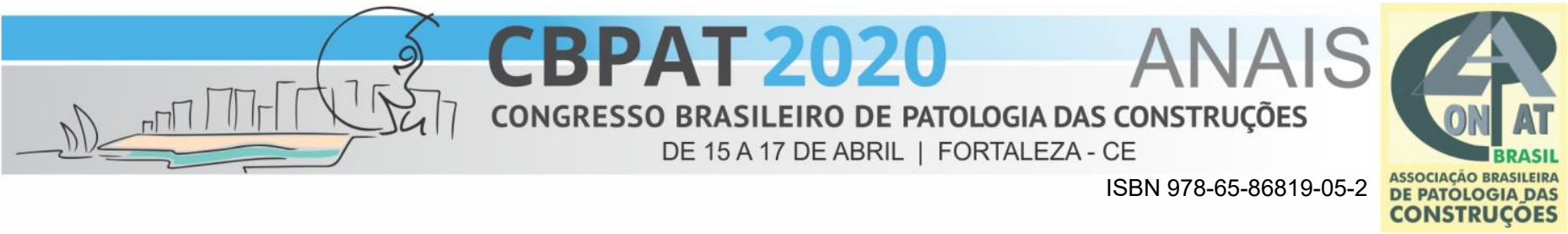

\section{RESULTADOS E DISCUSSÕES}

\subsection{Barrilete}

No barrilete verificou-se a diferença de bitolas nas tubulações com os respectivos registros de gaveta, sendo que esses possuíam 10 milímetros a menos que a respectiva tubulação (Figura 4). Tubulação de $50 \mathrm{~mm}$ e registro de gaveta de 40 $\mathrm{mm}$ (Figura $5 \mathrm{a}, \mathrm{b}$ e c), tubulação de $60 \mathrm{~mm}$ e registro de gaveta de $50 \mathrm{~mm}$ (Figura $5 \mathrm{~d} \mathrm{e} \mathrm{e}$ ).

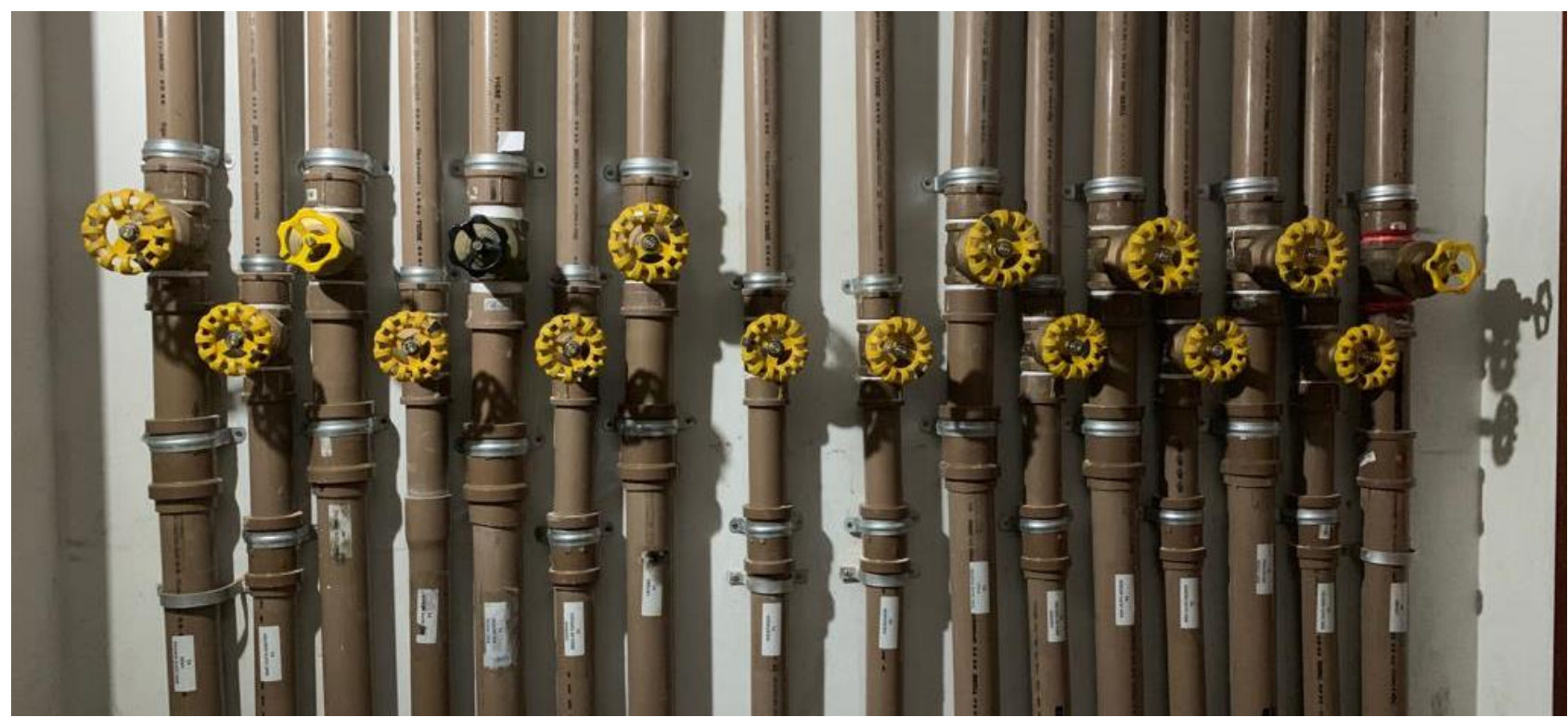

Figura 4: Tubulações e registros de gaveta do sistema hidráulico de água fria no barrilete do edifício.
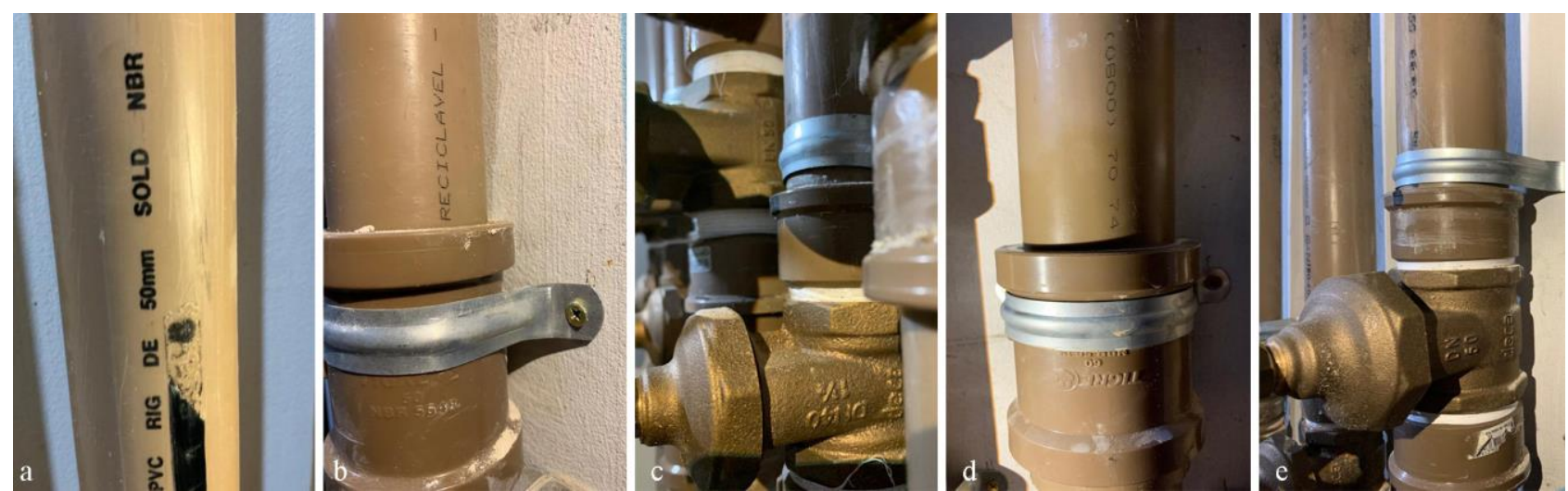

Figura 5: Tubulação e luva de $50 \mathrm{~mm}$ (a e b) com registro de gaveta de $40 \mathrm{~mm}$ (c) e tubulação e luva de $60 \mathrm{~mm}$ (d) com registro de gaveta de $50 \mathrm{~mm}$ (e).

O sistema hidráulico de água fria deve ser dimensionado de acordo com as recomendações de projeto e as normas existentes, como a ABNT NBR 5626:1998, preservando nos registros de gaveta a mesma bitola das respectivas tubulações.

Tal fato influencia diretamente na velocidade de escoamento do fluido, uma vez que, para manter a vazão constante, quando o fluido passa de uma tubulação mais grossa para uma tubulação mais fina, haverá uma variação dessa velocidade aumentando-a e consequentemente diminuindo a pressão do fluido sobre a parede da tubulação.

De acordo com NBR 5626 (ABNT, 1998), "as tubulações devem ser dimensionadas de modo que a velocidade da água, em qualquer trecho de tubulação, não atinja valores superiores a $3 \mathrm{~m} / \mathrm{s}$ ". Tal fato se deve ao escoamento de água, pois velocidades superiores ocasionam a vibração das paredes, gerando ruídos desagradáveis na tubulação, e favorecem a presença do fenômeno chamado "golpe de aríete". 
O registro de gaveta é uma válvula dotada de um obturador interno com formato de disco ou de cunha, que, ao ser totalmente acionada, obstrui completamente a passagem interna do fluxo líquido. É indicado para operar em serviços onde não há necessidade de operações frequentes, dado que o movimento de translação do obturador é muito lento a cada volta do volante, sendo particularmente recomendado onde a interrupação abrupta do fluxo poderia dar origem a "golpe de aríete".

O Quadro 1 apresenta a análise dos resultados da vistoria técnica realizada no barrilete do edifício.

Quadro 1 - Análise dos resultados da vistoria técnica realizada no barrilete do edifício.

\title{
Análise dos resultados
}

\begin{abstract}
Em consulta com profissionais especialistas em projeto de instalações hidrossanitárias, verificou-se que qualquer dano recorrente devido a diferença de bitola seria pontual. Durante a vistoria no barrilete observou-se a utilização de abraçadeiras que aparentemente já solucionaram o problema em questão, não sendo constatada mais nenhuma irregularidade.

Considerando a substituição dos registros de gaveta no barrilete e a abertura abrupta e sequencial dos mesmos, conforme relatado pelo síndico do edifício, fez-se viável levantar a possibilidade do acúmulo e retenção de ar no interior das tubulações, gerando bolsões que impedem a passagem de água, em razão do esvaziamento e rápido preenchimento das tubulações de distribuição de água fria sem tomar os devidos cuidados. Tal fato pode ocasionar diversos incidentes, como o rompimento de tubulações, visto que a água exerce uma maior pressão para expulsar o ar existente.

Os registros de gaveta do barrilete não apresentaram diferença de pressão para sua abertura parcial (60\%) ou total (100\%). Devendo-se então seguir a recomendação de deixá-los totalmente abertos.
\end{abstract}

Salienta-se que os registros de gaveta devem sempre ser usados totalmente abertos ou totalmente fechados, não sendo recomendado o uso em serviços de regulagem ou controle de vazão em que há estrangulamento do fluxo, com o obturador posicionado em ponto intermediário do seu curso, pois ficariam sujeitos a severas vibrações que poderiam comprometer seriamente o seu próprio funcionamento e outros componentes adjacentes, além de ocasionar ruídos indesejáveis. Além disso, sob fluxo com velocidade elevada, um obturador posicionado em ponto intermediário dentro do registro de gaveta pode causar cavitação, devida à abrupta redução da pressão absoluta total local a jusante, causando erosão nas superfícies das sedes e do próprio obturador.

\subsection{Unidades Autônomas}

Os ensaios de verificação da pressão estática no apartamento 101 foram realizados no ponto de ducha higiênica da suíte principal denominada "maior". A Figura 6 apresenta os resultados correspondentes nas seguintes condições:

a. Ensaio realizado com o manômetro e registro de gaveta do barrilete com $60 \%$ de abertura: pressão medida de aproximadamente $475 \mathrm{kPa}$;

b. Ensaio realizado com o manômetro e registro de gaveta do barrilete com 100\% de abertura: pressão medida de aproximadamente $475 \mathrm{kPa}$;

c. Ensaio realizado com a bomba de teste hidrostático e registro de gaveta do barrilete com $60 \%$ de abertura: pressão medida de aproximadamente $475 \mathrm{kPa}$;

d. Ensaio realizado com a bomba de teste hidrostático e registro de gaveta do barrilete com $100 \%$ de abertura: pressão medida de aproximadamente $475 \mathrm{kPa}$; 

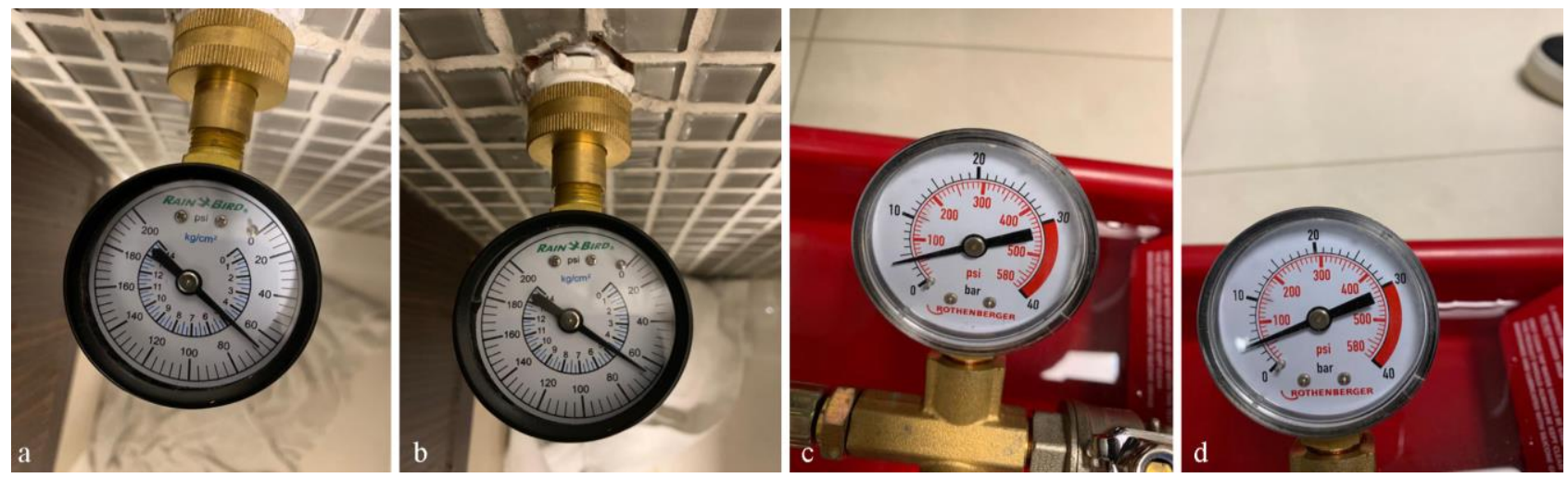

Figura 6: Resultados correspondentes à pressão estática no apartamento 101.

Os ensaios de verificação da pressão dinâmica no apartamento 101 foram realizados no ponto de ducha higiênica da suíte principal denominada "maior". A Figura 7 apresenta os resultados correspondentes nas seguintes condições:

a. Ensaio realizado com o manômetro e registro de gaveta do barrilete com $60 \%$ de abertura: pressão medida de aproximadamente $650 \mathrm{kPa}$;

b. Ensaio realizado com o manômetro e registro de gaveta do barrilete com 100\% de abertura: pressão medida de aproximadamente $650 \mathrm{kPa}$;

c. Ensaio realizado com a bomba de teste hidrostático e registro de gaveta do barrilete com $60 \%$ de abertura: pressão medida de aproximadamente $650 \mathrm{kPa}$;

d. Ensaio realizado com a bomba de teste hidrostático e registro de gaveta do barrilete com $100 \%$ de abertura: pressão medida de aproximadamente $650 \mathrm{kPa}$;
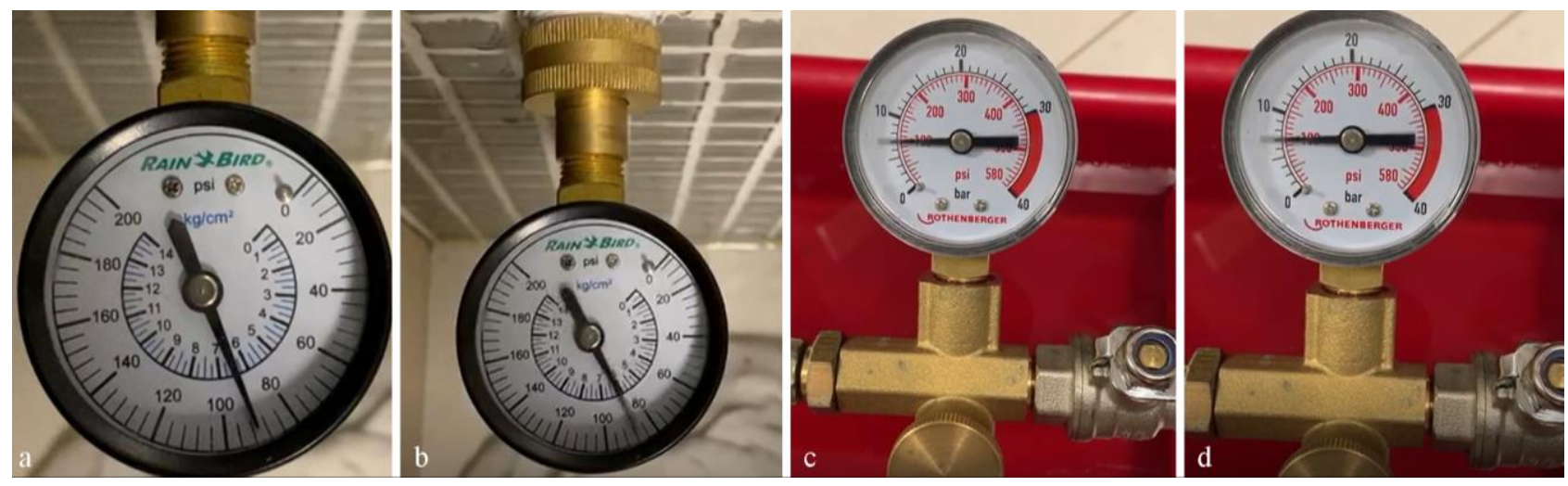

Figura 7: Resultados correspondentes à pressão dinâmica no apartamento 101.

Os ensaios de verificação da pressão estática no apartamento 601 foram realizados no ponto de saída de água fria do bidê da suíte principal denominada "maior". A Figura 8 apresenta os resultados correspondentes nas seguintes condições:

a. Ensaio realizado com o manômetro e registro de gaveta do barrilete com $60 \%$ de abertura: pressão medida de aproximadamente $325 \mathrm{kPa}$;

b. Ensaio realizado com o manômetro e registro de gaveta do barrilete com 100\% de abertura: pressão medida de aproximadamente $325 \mathrm{kPa}$.

Os ensaios de verificação da pressão dinâmica no apartamento 601 foram realizados no ponto de saída de água fria do bidê da suíte principal denominada "maior". A Figura 8 apresenta os resultados correspondentes nas seguintes condições:

c. Ensaio realizado com o manômetro e registro de gaveta do barrilete com $60 \%$ de abertura: pressão medida de aproximadamente $370 \mathrm{kPa}$;

d. Ensaio realizado com o manômetro e registro de gaveta do barrilete com 100\% de abertura: pressão medida de aproximadamente $370 \mathrm{kPa}$. 

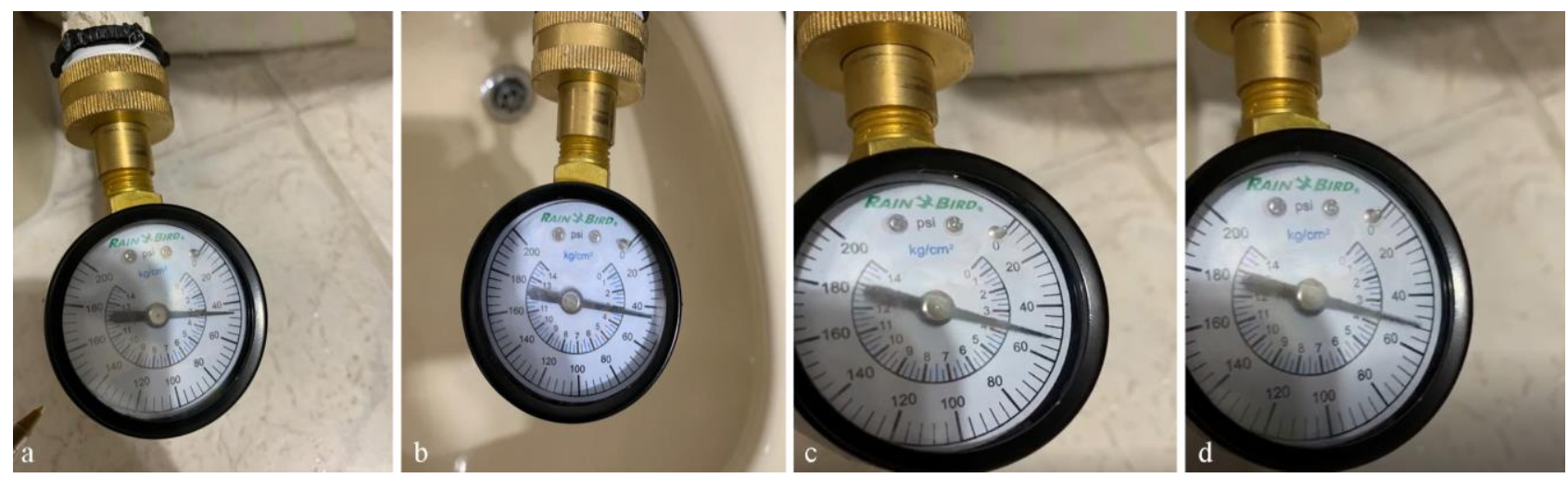

Figura 8: Resultados correspondentes à pressão estática no apartamento 601 (a e b) e resultados correspondentes à pressão dinâmica no apartamento 601 (c e d).

De acordo com NBR 5626 (ABNT, 1998):

a. Em condições estáticas (sem escoamento), a pressão da água em qualquer ponto de utilização da rede predial de distribuição não deve ser superior a $400 \mathrm{kPa}$.

b. A ocorrência de sobrepressões devidas a transientes hidráulicos deve ser considerada no dimensionamento das tubulações. Tais sobreperssões são admitidas, desde que não superem o valor de $200 \mathrm{kPa}$.

É importante ressaltar que: o conceito de pressão máxima independe do material utilizado nas tubulações, seja PVC, cobre ou ferro; e a pressão com valor acima do normatizado ocasiona ruído, "golpe de aríete" e a necessidade de constante manutenção nas instalações.

No apartamento 101 observou-se que a pressão do sistema hidráulico de água fria encontrava-se acima do máximo permitido, diferente do apartamento 601, onde a pressão do sistema de água fria estava dentro do limite permitido.

Os resultados dos ensaios evidenciaram que, independente do registro de gaveta do barrilete estar $60 \%$ ou $100 \%$ aberto, os valores verificados da pressão permaneceram inalterados.

A Tabela 1 apresenta os resultados correspondentes à pressão estática nos apartamentos.

Tabela 1 - Resultados correspondentes à pressão estática nos apartamentos 101 e 601.

\begin{tabular}{c|c|c|c|c}
\hline \multirow{2}{*}{ Apartamento } & $\begin{array}{c}\text { Abertura do } \\
\text { registro de gaveta }\end{array}$ & $\begin{array}{c}\text { Pressão } \\
\text { obtida }\end{array}$ & $\begin{array}{c}\text { Pressão máxima, } \\
\text { conforme NBR 5626 } \\
\text { (ABNT, 1998) }\end{array}$ & $\begin{array}{c}\text { Pressão máxima + sobrepressão } \\
\text { máxima, conforme NBR 5626 } \\
\text { (ABNT, 1998) }\end{array}$ \\
\hline \multirow{2}{*}{101} & $100 \%$ & $475 \mathrm{kPa}$ & & \multirow{2}{*}{$600 \mathrm{kPa}$} \\
\cline { 2 - 3 } & $60 \%$ & $475 \mathrm{kPa}$ & $400 \mathrm{kPa}$ & $600 \%$ \\
\cline { 2 - 3 } 601 & $100 \%$ & $325 \mathrm{kPa}$ & & \\
\hline
\end{tabular}

Observação: A utilização do manômetro e da bomba de teste hidrostático não apresentaram discrepância nos resultados.

Durante a realização dos ensaios, ao abrir e fechar a torneira de monocomando do banheiro da suíte principal nos apartamentos 101 e 601, detectou-se a presença do "golpe de aríete" através da oscilação da pressão obtida no manômetro e na bomba de teste hidrostático. Tal fato está diretamente relacionado à velocidade de água e à pressão na tubulação, enquanto está inversamente proporcional ao tempo de fechamento dos dispositivos de utilização, como torneira, registro ou qualquer outro equipamento que seja utilizado para o controle do fluxo.

A Tabela 2 apresenta os resultados correspondentes à pressão dinâmica nos apartamentos. 
Tabela 2 - Resultados correspondentes à pressão dinâmica nos apartamentos 101 e 601.

\begin{tabular}{c|c|c|c|c}
\hline \multirow{2}{*}{ Apartamento } & $\begin{array}{c}\text { Abertura do } \\
\text { registro de gaveta }\end{array}$ & $\begin{array}{c}\text { Pressão } \\
\text { obtida }\end{array}$ & $\begin{array}{c}\text { Pressão máxima, } \\
\text { conforme NBR 5626 } \\
\text { (ABNT, 1998) }\end{array}$ & $\begin{array}{c}\text { Pressão máxima + sobrepressão } \\
\text { máxima, conforme NBR 5626 } \\
\text { (ABNT, 1998) }\end{array}$ \\
\hline \multirow{2}{*}{101} & $100 \%$ & $650 \mathrm{kPa}$ & & \\
\cline { 2 - 3 } & $60 \%$ & $650 \mathrm{kPa}$ & \multirow{2}{*}{$400 \mathrm{kPa}$} & $600 \mathrm{kPa}$ \\
\cline { 2 - 3 } 601 & $100 \%$ & $370 \mathrm{kPa}$ & & \\
\hline
\end{tabular}

Observação: A utilização do manômetro e da bomba de teste hidrostático não apresentaram discrepância nos resultados.

De acordo com a literatura, os registros de gaveta apresentam estanqueidade plena apenas no início de sua vida útil, passando a não ser mais totalmente estanques após certo número de utilizações, em decorrência de desgastes entre o obturador e a sede, principalmente quando submetidos à pressões elevadas.

O "golpe de aríete" é um fenômeno que ocorre frequentemente nas instalações prediais de água fria quando a água, ao descer em velocidade elevada pela tubulação, é bruscamente interrompida (Figura 9). Isso provoca golpes de grande força nos equipamentos da instalação podendo causar ruídos e rompimentos em tubos e conexões.

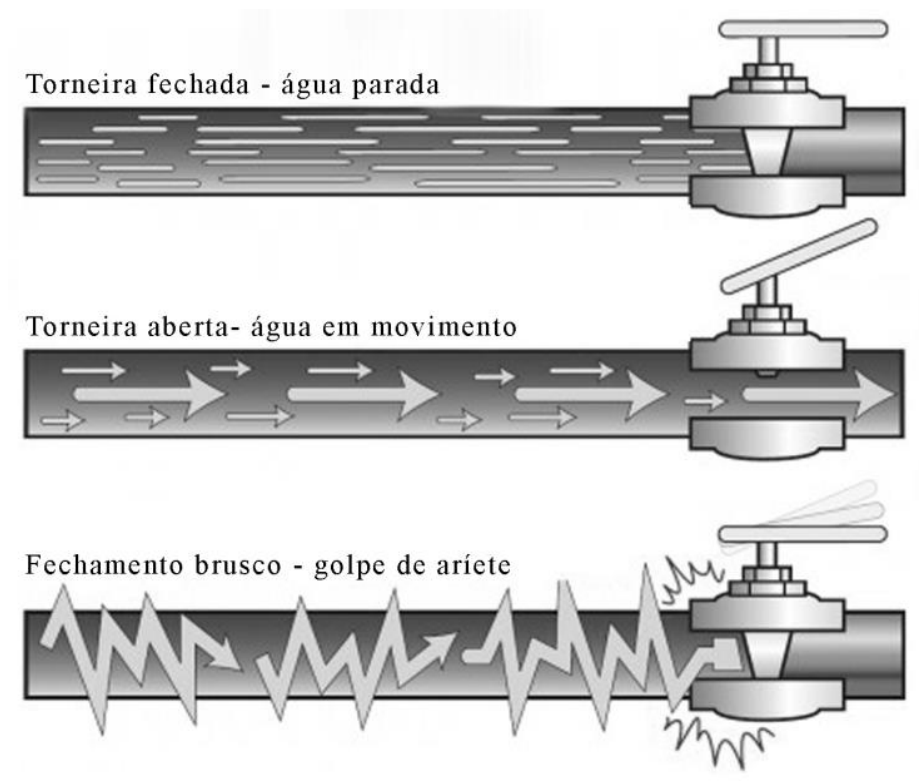

Figura 9: Golpe de aríete em tubulações hidráulicas de água fria. Fonte: Gnipper (2015).

A existência de pressão acima do máximo recomendado por norma, ocasiona desperdício de água, excessivo consumo, rupturas nas tubulações, conexões e flexíveis, "golpe de aríete" e fornecimento de água em quantidade superior à necessária nos pontos de utilização, chegando até mesmo a compromenter o funcionamento de equipamentos específicos.

Em edifícios mais altos, normalmente edifícios com mais de 13 pavimentos convencionais, o reservatório de água instalado sobre a cobertura gera diferentes pressões. Quanto maior a diferença entre o reservatório em relação a cota do ramal, maior a pressão. Ou seja, a pressão da água nos pontos de consumo dos pavimentos mais baixos será maior.

O Quadro 2 apresenta a análise dos resultados da vistoria técnica realizada nos apartamentos do edifício. 
Quadro 2 - Análise dos resultados da vistoria técnica realizada nos apartamentos 101 e 601 do edifício. Análise dos resultados

Verificou-se a recorrência de problema nos registros de gaveta dos banheiros dos apartamentos, os quais em sua maioria não estavam com completa interrupção do fluxo de água.

Verificou-se que a torneira de monocomando existente nos banheiros vistoriados tinha a tendência de dar um golpe acentuado na sua abertura e no seu fechamento. E as válvulas de descarga, possivelmente antigas e/ou desreguladas, também estavam relacionadas ao "golpe de aríete". Essas também podem ter sido desreguladas no momento da substituição dos registros de gaveta do barrilete devido à possível entrada de ar nas tubulações ja citadas anteriormente.

Pôde-se supor que a pressão do sistema não tenha mudado ao longo da vida útil e que tenha sempre trabalhado em sobrepressão, mas apenas agora, devido ao elevado tempo de uso e algumas intervenções, é que os rompimentos ocorreram.

Devido a pressão estática estar superior a $400 \mathrm{kPa}$ e a pressão dinâmica superior a $600 \mathrm{kPa}$, uma solução sugerida foi o uso de válvulas automáticas redutoras de pressão, as quais reduzem a pressão na entrada do sistema deixando-a menor e constante, evitando o "golpe de aríete" e o desgaste prematuro das instalações, assim como otimizando o consumo de água.

Observação: É importante destacar que durante a vistoria técnica não realizou-se ensaios de verificação da pressão nos pontos de água fria dos pavimentos abaixo do primeiro andar. Foi possível supor que nesses casos os resultados obtidos para as pressões estática e dinâmica seriam ainda maiores que os obtidos no apartamento 101 .

Os dispositivos reguladores de pressão substituem os reservatórios intermediários que reduzem a pressão da rede hidráulica a valores especificados em projeto, podendo ser instalados como um sistema intermediário (a partir do $5^{\circ}$ ou $6^{\circ}$ andar do edifício em análise) ou no subsolo (Figura 10).

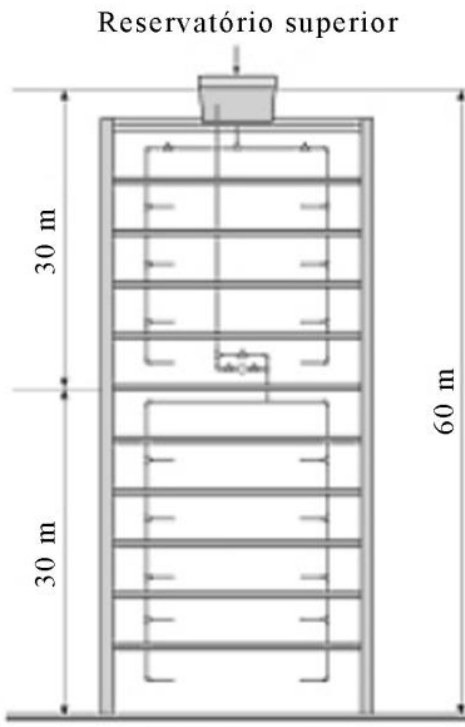

Válvula no meio do prédio

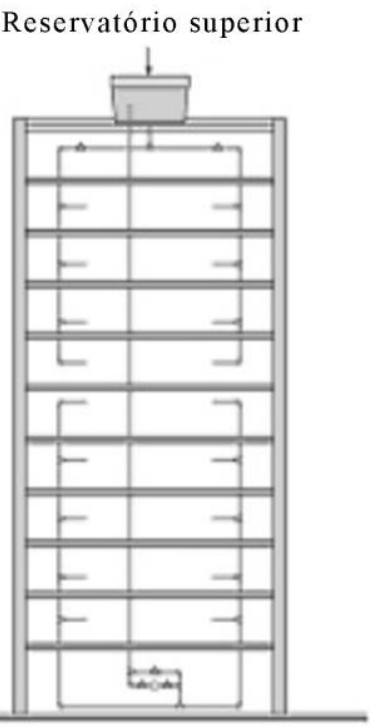

Válvula no subsolo

Figura 10: Sugestão de solução com válvulas redutoras de pressão no meio do prédio ou no subsolo.

Em geral, os edifícios possuem uma estação central de redutores de pressão, com dois equipamentos de grande porte instalados. Para prédios que possuem a medição individualizada de água, pode-se adotar a instalação de um redutor de pressão de menor porte, a fim de que cada apartamento receba a água com pressão adequada.

\section{CONCLUSÕES}

Com a finalidade de identificar as possíveis causas dos rompimentos em tubulações hidráulicas do sistema de água fria em edifício residencial multifamiliar após a substituição dos registros de gaveta do barrilete e também sugerir intervenções no sistema para eliminar os danos, fez-se uma inspeção in loco e foram executados ensaios de verificação da pressão nas tubulações hidráulicas. Diante dos resultados obtidos, pôde-se considerar que as manifestações 
patológicas existentes estavam relacionadas à diversos fatores, como: idade das tubulações, substituição dos registros de gaveta no barrilete e pressão acima dos limites normativos.

A interpretação do panorama no qual o edifício se encontrava foi de grande importância. Com aproximadamente 25 anos, as tubulações hidráulicas estavam acima do período de vida útil mínimo sugerido pela NBR 15575-1 (ABNT, 2013), estando mais suscetíveis à danos. Como a realização da troca de todas as peças sería inviável, sugeriu-se a correção dos problemas à medida em que fossem ocorrendo. Porém, algumas medidas poderíam ser tomadas visando diminuir o surgimento dos danos:

a. O mau funcionamento dos registros de gaveta nos apartamentos estava gerando o desperdício de água e não estava permitindo a manutenibilidade do sistema, uma vez que em situações de emergência que exigissem o fechamento pontual do sistema, não sería possível, sendo necessário o fechamento do registro de gaveta do barrilete, interrompendo o fluxo de água de todo o edifício. Então, sugeriu-se a verificação da estanqueidade dos registros de gaveta dos apartamentos e a troca do reparo, peça interna do registro, naqueles que apresentassem problemas.

b. A diferença de bitolas nas tubulações com os respectivos registros de gaveta no barrilete podería apresentar danos pontuais devido à elevada velocidade da água, como a vibração das paredes da tubulação. Mas, aparentemente já estava corrigida através da utilização de abraçadeiras, não sendo constatada mais nenhuma irregularidade.

c. Considerando o procedimento realizado para a abertura dos registros de gaveta do barrilete após a substituição dos mesmos, pôde-se presumir, em razão do esvaziamento e rápido preenchimento das tubulações de distribuição de água fria, que houve o acúmulo e retenção de ar no interior das tubulações, gerando bolsões de ar. Sugeriu-se que o sistema fosse previamente esvaziado para posterior abertura gradativa dos registros de gaveta, de modo a permitir a saída de ar. É importante salientar que os registros de gaveta devem operar com o sistema totalmente aberto ou totalmente fechado, pois o uso indevido em serviços de regulagem ou controle de vazão pode comprometer seriamente o seu funcionamento e também outros componentes adjacentes.

d. As válvulas de descarga desreguladas e/ou muito antigas do edifício, devido ao rápido fechamento, estavam causando sobrepressão no sistema e consequentemente o "golpe de aríete". Sugeriu-se que esses dispositivos fossem regulados ou substituídos por novos com fechamento lento.

e. Com o intuito de evitar a sobrepressão acima dos limites normativos no sistema predial de água fria do edifício e consequentemente os danos causados pelo "golpe de aríete". Sugeriu-se a utilização de válvulas automáticas redutoras de pressão como um sistema intermediário, podendo ser instaladas a partir do $5^{\circ}$ ou $6^{\circ}$ andar do edifício. Ou, caso houvesse a medição de água individualizada, sugeriu-se adotar a instalação de válvulas automáticas redutoras de pressão de menor porte, a fim de que cada apartamento recebesse a água com pressão adequada.

\section{REFERÊNCIAS}

ASSOCIAÇÃO BRASILEIRA DE NORMAS TÉCNICAS. NBR 5626: Instalação predial de água fria. Rio de Janeiro, 1998.

NBR 15575: Edificações habitacionais - Desempenho. Rio de Janeiro, 2013.

CARVALHO JÚNIOR, R. de. Patologia em sistemas prediais hidráulico-sanitários. 3 ed. São Paulo: Bluncher, 2018.

LICHTENSTEIN, N. B. Patologia das construções: procedimento para diagnóstico e recuperação. Boletim Técnico: BT/PC/06. São Paulo, EPUSP, 1985.

PADARATZ, I. J. Patologia da Construção: a falta de qualidade. In: III Simpósio de Desempenho de Materiais de Construção e Componentes de Construção Civil, Florianópolis/SC, outubro de 1991, p 01-10.

THOMAZ, E. Trincas em edifícios: causas, prevenção e recuperação. 1 ed. São Paulo: Pini, 2014. 